\title{
Potensi Pasar Pembiayaan KMF Purna BRI Syariah iB Dengan Akad Murabahah (Pendekatan Analisis SWOT)
}

\author{
Soeharjoto ${ }^{1}$, Agnes Panca Dewi ${ }^{2}$ \\ ${ }^{1,2}$ Universitas Trisakti

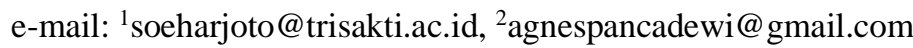

\begin{tabular}{ccc}
\hline Diterima & Direvisi & Disetujui \\
$01-01-2020$ & $01-02-2020$ & $01-03-2020$ \\
\hline
\end{tabular}

\begin{abstract}
Abstrak - Perbankan dan lembaga keuangan lainnya mayoritas membidak pasar pada masyarakat usia produktif tetapi BRI Syariah iB justru para pensiunan. Untuk itu, penetian ini bertujuan untuk mengetahui potensi pasar pembiayaan KMF Purna dengan akad Murabahah di BRI Syariah iB. Metode yang digunakan dalam penelitian ini analisis SWOT. Adapun hasilnya pembiayaan ini memiliki mekanisme yang terstruktur dengan baik dan sesuai ketetapan OJK yang menangani perbankan syariah, sehingga dapat menghindari terjadinya kesalahpahaman yang dapat merugikan dan mengurangi kepercayaan dari kedua belah pihak. Hal ini, menyebabkan pembiayaan KMF Purna dengan akad Murabahah di BRI Syariah iB memiliki potensi pasar yang besar karena pangsa pasarnya para pensiunan yang membutuhkan bantuan dana dalam memenuhi kebutuhan barang dan jasa serta nasabahnya pada usia dewasa akhir yang menginginkan rasa aman. Untuk itu, BRI Syariah iB dalam pembiayaan KMF Purna dengan akad Murababah dapat mengoptimalkan pasar dengan meningkatkan sumber daya manusia, teknologi digital, pemasaran, dan kerjasama dengan perusahaan lain agar dapat meningkatkan daya saing dengan lembaga pembiayaan lainnya.
\end{abstract}

Kata Kunci: kepemilikan multi faedah, pensiunan, murabahah, potensi pasar

\begin{abstract}
Banks and other financial institutions open majority the market to the productive age community but BRI Syariah iB focus on retiree. Purpose of this research is to determine market potential of KMF Purna financing with the Murabahah contract at BRI Syariah iB. SWOT analysis is used as a method in this research. Result shown, that this financing has a mechanism that well structured and in accordance with the provisions of the OJK which deals with Islamic banking, to avoid misunderstandings that can harm and reduce the trust of both parties. Result of KMF Purna with the Murabahah contract financing at BRI Syariah iB having a great potential market because focus on retiree market share who need financial assistance for goods and services fulfillment as well as their customers at an late adulthood who want a sense of security. For this reason, BRI Syariah iB in financing KMF Purna with the Murababah agreement can optimize the market by increasing human resources, digital technology, marketing, and collaboration with other companies in order to increase competitiveness with other financing institutions.
\end{abstract}

Keywords: multi utility ownership, retiree, murabahah, market potential

\section{PENDAHULUAN}

Penduduk Indonesia mayoritas beragama Islam, sehingga banyak yang menghendaki kegiatan ekonomi menggunakan prinsip syariah (Nugroho, Utami, Doktorlina, Soeharjoto, \& Husnadi, 2017). Untuk itu, dalam menunjang aktivitas ekonominya pemerintah menerapkan perbankan dengan dual banking system yakni konvensional dan syariah (Soekapdjo, Tribuddhi, \& Nugroho, 2019). Kebijakan tersebut, telah memberikan peluang besar pada perbankan untuk mengembangkan usahanya sebagai lembaga intermediary dan dapat berperan serta dalam pembangunan di Indonesia (Soeharjoto, Tribudhi, Hariyanti, \& Tajib, 2020). Hal ini, membuat semakin pesatnya kemajuan perbankan syariah karena pemerintah memberikan izin pada bank konvensional untuk turut serta membuka unit usaha syariah (Taga, Nawawi, \& Kosim, 2019). Perbankan syariah merupakan bank yang menerapkan sistem bagi hasil (Fadilah \& Soeharjoto, 2016). Namun, sebelum melakukan persetujuan pembiayaan perlu dilakukannya akad, agar tidak terjadi adanya pihak yang merasa dirugikan, sehingga dapat terhindarnya perselisihan dari kedua belah pihak (Hanafi, 2018).

P.T. Bank Rakyat Indonesia Syariah (BRI Syariah) merupakan perbankan di Indonesia yang telah berhasil mengembangkan jasa keuangan dengan 
menerapkan prinsip syariah (Muhlis, 2018). Pada 2 Juli 2007, telah diresmikan logo iB (Islamic Banking) dengan tujuan agar perbankan syariah di Indonesia lebih mudah dikenali dan menjadi salah satu pembeda dengan perbankan konvensional. Logo iB dengan penulisan huruf ' $i$ ' kecil pada 'iB' yang menggambarkan bahwa Islam merupakan agama yang rendah hati, lembut, menyejukkan, halus dan menghargai. Untuk itu, logo iB secara keseluruhan memiliki arti bahwa iB merupakan sebuah kristalisasi dari nilai-nilai utama sistem perbankan syariah yang modern, transparan, berkeadilan, seimbang dan beretika. Adanya perkembangan dari perbankan syariah dengan menggunakan logo ini, akhirnya BRI Syariah menjadi BRI Syariah iB.

Hal ini, tidak terlepas dari beberapa produk yang dikembangkan pada BRI Syariah iB dan salah satunya Kepemilikan Multi Faedah (KMF) untuk karyawan yang perusahaannya bekerjasama dengan BRI Syariah iB dalam Employment Benefit Program (EmBP), dengan menggunakan akad jual beli (Murabahah) atau sewa menyewa (ijarah). KMF merupakan gabungan dari produk Kepemilikan Multi Guna Purna (KMG) dan Kepemilikan Multi Jasa (KMJ). KMF Purna BRI Syariah iB merupakan produk pembiayaan yang inovatif dan dibutuhkan masyarakat banyak tetapi banyak lembaga keuangan yang belum menyadari potensi pasarnya (Mukhlisin \& Suhendri, 2018). Untuk itu, program ini dikonsentrasikan pada kepemilikan multi faedah yang menggunakan fasilitas pembiayaan untuk pensiunan dalam memenuhi kebutuhan barang atau jasa yang menggunakan akad dengan pembayaran secara angsuran yang telah ditetapkan setiap bulannya.

Jenis pembiayaan berdasarkan akad jual beli dapat dilakukan secara Murabahah, Salam, dan Istis'na (Yunus, Hamdani, \& Shofia, 2018). Dalam perkembangan skim muamalah, yang banyak digunakan perbankan syariah adalah jual beli dengan akad Murabahah (Hakim \& Anwar, 2017). Pembiayaan ini, diatur dalam Fatwa DSN NO04/MUI/IV/2000. Dalam penerapan akadnya sederhana karena hanya perlu adanya kesepakatan dari penjual terhadap harga perolehan dan keuntungan yang diperolehnya. Pada pembiayaan Murabahah, bank bertindak sebagai penjual dan nasabah sebagai pembeli (Alawiyah, 2016). Harga jual merupakan harga beli bank dari pemasok ditambah keuntungan. Untuk itu, kedua pihak perlu menyepakati harga jual dan jangka waktu pembayaran.

Pembiayaan KMF Purna BRI Syariah iB yang menggunakan akad Murabahah dapat berkembang baik dan dibutuhkan masyarakat, terutama para pensiunan dalam memenuhi kebutuhan konsumsinya yang ingin menerapkan prinsip syariah, agar memperoleh keberkahan. Keberhasilan produk pembiayaan ini perlu didukung dengan potensi yang dimilikinya. Untuk itu, perlu dilakukan penelitian analisis SWOT potensi pasar pembiayaan KMF Purna dengan akad Murabahah di BRI Syariah iB.

\section{METODE PENELITIAN}

Penelitian ini bertujuan untuk mengetahui potensi pasar KMF Purna dengan akad Murabahah pada BRI Syariah iB. Metode yang digunakan dalam penelitian ini deskripitif dengan pendekatan kualitatif, yang pengumpulan datanya menggunakan studi literatur, observasi, wawancara, dan dokumentasi (Moleong, 2009). Dalam melakukan analisis menggunakan Strengths, Weaknesses, Opportunities, and Threats (SWOT) (Rangkuti, 2016). Untuk melakukan analisisnya menggunakan faktor eksternal dan internal (Kotler, Wong, Saunders, \& Armstrong, 2018). Faktor internal menggunakan produk berupa jenis dan kualitas, harga produk, promosi dengan fasilitas pembiayaan dan pemanfaatan media, sumber daya manusia dengan karyawan bank dan peran masyarakat. Faktor eksternal berupa kondisi sosial masyarakat, ekonomi, penerapan teknologi informasi, serta daya saing. Dalam analisis SWOT menampilkan delapan kotak dalam bentuk matriks, yaitu dua kotak sebelah kiri menampilkan faktor eksternal (Opportunities dan Threats), dua kotak paling atas menampilkan faktor internal. (Strengths dan Weaknesses) dan empat kotak lainnya merupakan isu-isu strategis yang timbul sebagai hasil pertemuan antara faktor eksternal dan internal. Alternatif strategi adalah hasil dari matriks analisis SWOT yang menghasilkan berupa strategi SO, WO, ST dan WT. Alternatif strategi yang dihasilkan minimal 4 buah strategi sebagai hasil dari analisis matriks SWOT.

\section{HASIL DAN PEMBAHASAN}

P.T. Bank Rakyat Indonesia Syariah Tbk., merupakan pengembangan dari akuisisi yang dilakukan P.T. Bank Rakyat Indonesia Tbk. (BRI) terhadap Bank Jasa Arta pada 19 Desember 2007. BRI Syariah iB akhirnya resmi beroperasi pada 17 November 2008 pasca memperoleh izin usaha dari Bank Indonesia melalui surat no. 10/67/Kep.GBI/DBG/2008 pada 16 Oktober 2008. Kemudian, pada 19 Desember 2008 Unit Usaha Syariah BRI dilebur ke dalam BRI Syariah iB. Namun, hasil dari proses spin off tersebut berlaku efektif pada 1 Januari 2009. Kebijakan ini, dilakukan BRI karena melihat adanya peluang dan potensi yang besar dari BRI Syariah iB untuk dapat masuk di segmen perbankan syariah. Untuk itu, BRI Syariah iB memfokuskan diri dengan membidik berbagai segmen masyarakat yang menginginkan aktivitas ekonomi dengan menggunakan prinsip syariah. Adapun latar belakangnya karena BRI Syariah iB memiliki kapabilitas tinggi sebagai bank ritel modern dan terkemuka, dengan konsep layanan finansial yang sesuai dengan kebutuhan nasabah. Pada 2018, BRI Syariah iB melakukan initial public offering (IPO) pada 9 mei 2018 di Bursa Efek Indonesia. IPO ini, 
menjadikan BRI Syariah iB sebagai anak usaha Badan Usaha Milik Negara (BUMN) yang bergerak dibidang syariah yang pertama untuk melaksanakan penawaran umum saham perdananya. Keberhasilan BRI Syariah iB tidak terlepas dari pelayanan yang diberikan dan produk yang dimilikinya. Hal ini terlihat dari beberapa kemudahan yang diberikan dalam mekanisme pelayanan untuk produk yang dibuatnya, agar sesuai dengan keinginan dan kebutuhan nasabah terutama pada KMF Purna BRI Syariah iB.

\section{Mekanisme Pembiayaan KMF Purna BRI Syariah iB dengan akad Murabahah.}

Pembiayaan KMF Purna BRI Syariah iB merupakan pembiayaan bank kepada nasabah perorangan atau badan hukum untuk membiayai kebutuhan konsumtif karyawan terutama para pensiunan, dengan limit pembiayaan 100 juta. Persyaratan yang mudah, proses pembiayaan cepat, dan angsuran ringan serta tetap hingga jatuh tempo adalah nilai plus dari produk pembiayaan KMF Purna BRI Syariah iB. Adanya keunggulan tersebut, diharapkan dapat digunakan karyawan terutama para pensiunan agar dapat tetap menjalankan kehidupannya dan turut berkontribusi terhadap perekonomian nasional secara optimal (Darmawan \& Ridlwan, 2018).

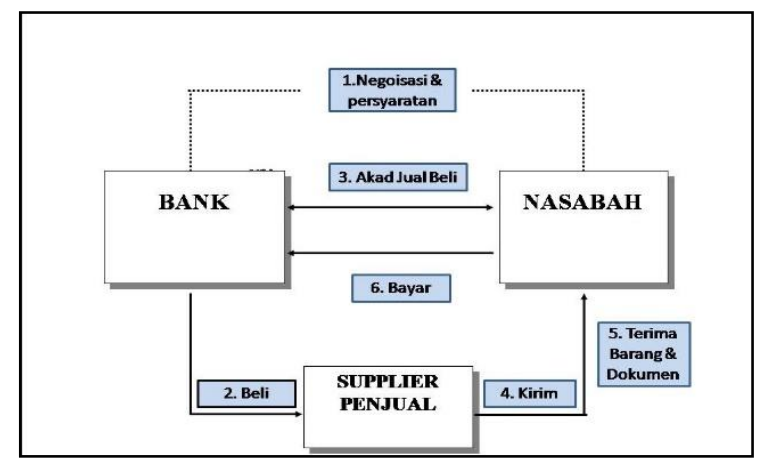

Gambar 1. Skema Transaksi Murabahah

KMF Purna BRI Syariah iB, merupakan produk yang ditujukan untuk nasabah yang berpenghasilan atau memiliki gaji dari instansi (payroll). Adapun daya tarik dari produk ini adalah tidak diperlukannya jaminan dan hanya menggunakan Surat Keputusan kerjanya, kemudian nasabah dapat menikmati fasilitas pembiayaan di BRI Syariah iB. Akad yang digunakan pada produk KMF Purna BRI Syariah iB adalah Murabahah.

Munculnya konsep dari pembiayaan Murabahah pada bank syariah dikarenakan pihak bank tidak memiliki barang yang diinginkan oleh nasabah, sehingga pihak bank perlu melakukan transaksi pembelian atas barang yang diinginkan nasabah pada pihak lain atau sering disebut sebagai supplier (Winarto \& Falah, 2020). Untuk itu, pihak bank dapat bertindak sebagai penjual dan pembeli. Namun, pihak bank akan menjualnya kembali barang yang sudah dibeli kepada nasabah banknya dengan ketentuan harga telah disesuaikan yakni berupa harga beli ditambah margin yang telah disepakati. Ada bebarapa karakteristik dari pembiayaan Murabahah yang diterapkan pada perbankan syariah yakni:

1. Akad yang digunakan merupakan jual beli. Dalam implikasinya, dari penggunaan akad jual beli yang mengharuskan adanya penjual, pembeli, dan barang yang dijual. Bank syariah selaku penjual harus menyediakan barang untuk nasabah yang dalam hal ini adalah sebagai pembeli. Untuk itu, nasabah berkewajiban untuk membayar barang yang telah diserahkan oleh bank syariah.

2. Harga yang tetapkan oleh pihak penjual (bank syariah) tidak dipengaruhi oleh frekuensi dari waktu pembayaran. Jadi, harga yang ada hanyalah satu yaitu harga yang telah disepakati oleh bank syariah dan nasabah.

3. Keuntungan dalam pembiayaan Murabahah dalam bentuk margin penjulan dan sudah termasuk harga penjualan. Adanya ketentuan dari keuntungan yang diperoleh sewajarnya, sehingga dapat dilakukan kesepakatan antara pihak bank syariah dan nasabah.

4. Untuk pembayaran barang dapat dilakukan secara angsuran. Jadi, pihak nasabah berhutang kepada pihak bank syariah, karena belum melunasi kewajiban terhadap pembayaran barangnya. Untuk itu, angsurannya pada pembiayaan Murabahah tidak terikat dengan jangka waktu pembayaran yang ditetapkan.

5. Dalam pembiayaan Murabahah memungkinkan adanya jaminan, karena sifat dari pembiayaan Murabahah merupakan jual beli tetapi pembayaraanya tidak dilakukan secara tunai. Untuk itu, bank syariah perlu memberlakukan prinsip kehati-hatian dengan mengenakan jamian kepada nasabah.

Namun demikian, dalam praktiknya akad jual beli Murabahah dapat dilakukan sebelum barang yang secara prinsip menjadi milik bank. Hal ini, tentunya tidak sesuai dengan ketentuan Fatwa MUI No. 04/DSN-MUI/IV/2000 tanggal 1 April 2000 (26 Dzulhijah $1420 \mathrm{H}$ ), yang menetapkan bahwa jika bank hendak mewakilkan kepada nasabah untuk membeli barang dari pihak ketiga, maka akad jual beli Murabahah harus dilakukan setelah barang secara prinsip milik bank. Masalah ini, tentunya perlu diperhatikan oleh pihak bank syariah, karena masalah ini dapat berpotensi untuk menurunkan citra dari bank syariah.

Adanya ketidaksesuaian ini, dari pihak Dewan Pengawas Syariah (DPS) masih menganggap berada dalam koridor syariah. Hal ini, dapat terjadi karena selama ketidaksesuaian ini masih berada pada tataran aplikasinya, namun tidak masuk ke dalam ranah wilayah prinsip. Untuk itu, pembiayaan KMF 
Purna BRI Syariah iB masih sesuai dengan prinsip syariah, sehingga keberadaannya masih layak. Adapun perbedaan antara Murabahah dan kredit konvensional adalah sebagai berikut :

1. Pada dasarnya prinsip yang digunakan pada Murabahah adalah akad jual beli tetapi pada kredit konvensional adalah pinjam meminjam.

2. Hubungan antara bank dan nasabahnya pada praktiknya di bank syariah adalah penjual dan pembeli tetapi pada kredit konvensional adalah kreditur dan debitur.

3. Murabahah menghendaki hanya terdapat satu harga dan tidak tergantung dengan jangka waktu pembayarannya, tetapi pada kredit konvensional mengharuskan adanya perbedaan pembayaran, yang disesuaikan dengan jangka waktu yang telah ditentukan. Jadi, dengan semakin lama waktu pembayarannya akan semakin besar jumlah tanggungan yang harus dibayar.

4. Murabahah dalam paktiknya akan memberikan keuntungan dalam bentuk margin penjualan, tetapi pada kredit konvensional berdasarkan tingkat suku bunga.

\section{Prosedur umum pembiayaan KMF Purna BRI Syariah iB.}

Pembiayaan KMF Purna BRI Syariah iB merupakan produk alternatif pembiayaan dari bank BRI Syariah iB, yang diperuntukan bagi karyawan yang sudah pensiunan. Pembiayaan ini menggunakan akad Murabahah. Adapun prosedur untuk melakukan pengajuan pembiayaan KMF Purna BRI Syariah iB adalah:

1. Nasabah datang ke bank dan mengajukan permohonan pembiayaan. Pihak pelaksana dan administrasi KMF Purna BRI Syariah iB akan melakukan pengecekan terhadap kelengkapan persyaratan yang telah diserahkan nasabah.

2. Pasca seluruh persyaratan yang ada telah dipenuhi, pihak bank akan melakukan analisis secara administratif dan apabila diperlukan pihak bank dapat melakukan survey ke lapangan.

3. Adanya hasil analisis dari KMF Purna BRI Syariah iB, dapat digunakan sebagai dasar dalam pembuatan proposal pembiayaan, untuk dapat diajukan pada komite pembiayaan dan kepala cabang.

4. Apabila proposalnya telah disetujui oleh komite pembiayaan dan kepala cabang, selanjutnya pihak bank akan melakukan akad atau kontrak perjanjian dengan nasabah.

5. Pasca dilakukannya akad antara pihak bank dan nasabah, kemudian pihak bank akan mencairkan dana pembiayaan, dengan cara menstransfer langsung dananya ke rekening nasabah.

6. Namun demikian, apabila akad telah ditandatangani kedua belah pihak, maka nasabah langsung memiliki kewajiban terhadap bank, yakni berupa pembayaran angsuran pembiayaan dengan besaran dan jangka waktu yang sudah disepakati dalam perjanjian.

\section{Analisa matrik SWOT pembiayaan KMF Purna BRI Syariah iB.}

Pada analisis SWOT diperoleh matriks dari hasil kekuatan (strengths), kelemahan (weakness), peluang (opportunities), dan ancaman (Threats) potensi pasar pembiayaan KMF Purna BRI Syariah iB. Adapun hasilnya adalah:

1. Kekuatan (strengths) berupa terhindar dari riba yang membuat rasa aman, angsuran tetap sampai lunas, jumlah plafon pembiayaan yang dapat disesuaikan dengan kebutuhan nasabah, margin yang kompetitif, proses pengajuannya mudah dan cepat, dan jangka waktu angsuran pembiayaan yang panjang.

2. Kelemahan (weakness) berupa masih kurangnya promosi yang dilakukan dengan menggunakan media cetak dan elektronik, masih menghendaki adanya persyaratan agunan terutama untuk pembiayaan KMF Purna BRI Syariah iB yang memiliki limit 50 juta rupiah-100 juta. rupiah.

3. Peluang (opportunities) berupa dapat melakukan promosi secara efektif dan efisien dengan menggunakan media elektronik, dan sudah memiliki undang-undang pendukung bank syariah.

4. Ancaman (Threats) berupa bayaknya pesaing baru dari bank syariah maupun bank konvensional dan fintech, serta masih banyaknya masyarakat yang belum mengetahui pembiayaan KMF Purna BRI Syariah iB.

\section{Rancangan strategi potensi pasar pembiayaan KMF Purna BRI Syariah iB.}

Hasil dari analisis SWOT dapat dibuat strategi potensi pasar pembiayaan KMF Purna BRI Syariah iB dengan membuat strategi Strength Opportunity (SO), Strength Threats (ST), Weakness Opportunity (WO), dan Weakness Threat (WT). Adapun hasilnya adalah:

1. Strategi Strength Opportunity (SO), merupakan strategi yang lebih mengutamakan kekuatan dan memanfaatkan peluang yang ada. Strategi ini dapat digunakan untuk mendukung kebijakan agar pertumbuhan pembiayaan KMF Purna BRI Syariah iB lebih cepat dengan membuat strategi pemasaran yang lebih efektif dan efisien dalam memasarkan produk, membangun brand image yang kuat di masyarakat dengan memanfaatkan acara event dan pameran, mengoptimalkan penggunaan teknologi digital, mulai memperkenalkan keunggulan pembiayaan $\mathrm{KMF}$ Purna BRI Syariah iB sesuai dengan segmentasi yang tetapkan, memberikan edukasi secara komprehensif pada masyarakat manfaat dari penggunaan produk yang ada di bank syariah.

2. Strategi Strength Threat (ST), merupakan strategi dengan memanfaatkan kekuatan dalam 
mengatasi tantangan yang ada berupa meningkatkan sistem dan prosedur pelayanan nasabah agar pelayanan menjadi lebih baik, dan aktif dalam kegiatan ilmiah terutama pada bidang syariah.

3. Strategi Weakness Opportunity (WO), merupakan strategi yang dapat meminimalkan kelemahan intern dengan cara memanfaatkan peluang yang ada agar dapat memperbaiki kondisi internal berupa melakukan ekspansi jaringan dengan membuka kantor cabang baru sehingga akan terciptanya jaringan pemasaran yang lebih luas, memanfaatkan event dan acara pameran untuk mempromosikan produk kepada masyarakat, mengoptimalkan penggunaan teknologi digital dan kemampuan sumber daya manusia di BRI Syariah iB dengan dengan memberikan pendidikan dan pelatihan.

4. Strategi Weakness Threat (WT), merupakan strategi yang dapat meminimalkan kelemahan internal dengan memberikan pelatihan dalam menghadapi tantangan berupa mengoptimalkan pemasaran dalam menghadapi agresivitas para pesaing, melakukan inovasi dalam memasarkan produk, memberikan edukasi yang komprehensif pada masyarakat mengenai produk pembiayaan yang ada di bank syariah.

Berdasarkan hasil analisis SWOT yang dilakukan terhadap pembiayaan KMF Purna BRI Syariah iB dengan akad Murabahah memiliki potensi pasar yang besar karena pangsa pasar yang dituju terfokus pada para pensiunan yang memang membutuhkan bantuan dana untuk memenuhi kebutuhan barang dan jasa serta dapat membuat nasabahnya lebih aman dengan menggunakan prinsip syariah yang memang dapat menghindari terjadinya riba. Hal ini diterapkan karena para pensiunan telah memasuki usia dewasa akhir (late adulthood) (Hurlock, 2012). Pada usia ini, semakin matang kejiwaannya karena mereka memahami jati diri dan makna dari kehidupan, sehingga ada peningkatan kesadaran terhadap religius termasuk dalam bidang ekonomi (Iswati, 2018). Untuk itu, pihak BRI Syariah iB perlu meningkatkan sumber daya manusia, teknologi digital, pemasaran, dan kerjasama dengan perusahaan lain agar dapat bersaing dengan lembaga pembiayaan lainnya.

\section{KESIMPULAN}

P.T. Bank Rakyat Indonesia merupakan perbankan BUMN di Indonesia yang berhasil mengembangkan perbankan syariah. Untuk itu, dalam memenuhi kebutuhan dan potensi pasar pada masyarakat yang ingin menerapkan prinsip syariah dikembangkanlah BRI Syariah iB. Namun, kebanyakan perbankan dan lembaga keuangan lainya membidak pasar pada masyarakat yang masih pruduktif, tetapi BRI Syariah iB dengan inovatifnya lebih tertarik untuk memanfaatkan peluang pasar pada para pensiunan dengan membuat pembiayaan
KMF Purna BRI Syariah iB. Adapun hasil dari penelitian yang telah dilakukan dengan menggunakan analisis SWOT terhadap potensi pasar pembiayaan KMF Purna BRI Syariah iB dapat diperoleh hasil dari mekanisme pembiayaan KMF Purna BRI Syariah iB yang sudah dilaksanakan secara terstruktur dengan baik dan sesuai ketetapan peraturan Otoritas Jasa Keuangan (OJK) yang menangani perbankan syariah terutama dalam hal penerapan akad Murababah, sehingga dapat menghindari terjadinya kesalahpahaman yang dapat merugikan dan mengurangi kepercayaan dari kedua belah pihak. Pembiayaan ini, memiliki potensi pasar yang besar karena pangsa pasarnya para pensiunan yang memang membutuhkan bantuan dana untuk memenuhi kebutuhan barang dan jasa serta nasabahnya pada usia dewasa akhir yang ingin hidup dengan rasa aman, sehingga pembiayaan yang menggunakan prinsip syariah dapat menghindari terjadinya riba. BRI Syariah iB dalam pembiayaan KMF Purna dengan akad Murababah agar dapat mengoptimalkan pasar yang ada, perlu meningkatkan sumber daya manusia, teknologi digital, pemasaran, dan kerjasama dengan perusahaan lain agar dapat bersaing dengan lembaga pembiayaan lainnya.

\section{REFERENSI}

Alawiyah, I. T. (2016). Konsep Produk Murabahah dalam Perspektif Ekonomi Syari'Ah. Mahkamah, 1(1), 2527-4422.

Darmawan, Z. C., \& Ridlwan, A. A. (2018). Pengaruh Kualitas Pelayanan terhadap Kepuasan Nasabah Perbankan Syariah. Al-Tijary: Jurnal Ekonomi dan Bisnis Islam, 3(2), 107-115. https://doi.org/10.21093

Fadilah, N., \& Soeharjoto. (2016). Determinasi Permintaan Pembiayaan Konsumsi. Media Ekonomi, 24(1), 27-36. https://doi.org/http://dx.doi.org/10.25105/me.v 24i1.3786

Fatwa DSN MUI No. 04/DSNMUI/IV/2000 Tentang MURABAHAH

Hakim, L., \& Anwar, A. (2017). Pembiayaan Murabahah pada Perbankan Syariah dalam Perspektif Hukum di Indonesia. Al-Urban: Jurnal Ekonomi Syariah dan Filantropi Islam, 1(2),

212-223. https://doi.org/https://doi.org/10.22236/alurba n_vol1/is2pp212-223

Hanafi, D. (2018). Akad dalam Transaksi Ekonomi Syariah. Sulesana, 12(2), 143-167. https://doi.org/https://doi.org/10.24252/sulesan a.v12i2.757

Hurlock, E. B. (2012). Psikologi Perkembangan (Edisi 5). Jakarta: Erlangga.

Iswati. (2018). Karakteristik Ideal Sikap Religiusitas pada Masa Dewasa. At-Tajdid: Jurnal Pendidikan dan Pemikiran Islam, 2(1), 58-71. https://doi.org/http://dx.doi.org/10.24127/att.v 2i01.859 
Kotler, P., Wong, V., Saunders, J., \& Armstrong, G. (2018). Principles of Marketing. UK: Pearson.

Moleong, L. J. (2009). Metode Penelitian Kualitatif. Bandung: Remaja Rosdakarya.

Muhlis. (2018). Penerapan Model Z-Score untuk Prediksi Kebangkrutan Bank Bri Syariah Tahun 2014-2016. Jurnal Syari'ah dan Hukum Diktum, 16(1), 81-97. https://doi.org/https://doi.org/10.35905/diktum .v16i1.523

Mukhlisin, A., \& Suhendri, A. (2018). Strategi Pengembangan Produk Bank Syariah di Indonesia. Jurnal Ekonomi Syariah, 3(2), 190-199.

https://doi.org/https://dx.doi.org/10.30736/jesa .v3i2.47

Nugroho, L., Utami, W., Doktorlina, C. M., Soeharjoto, \& Husnadi, T. C. (2017). Islamic Banking Capital Challenges to Increase Business Expansion (Indonesia Cases). International Journal of Commerce and Finance, 3(2), 1-10.

Rangkuti, F. (2016). Analisis SWOT: Teknik Membedah Kasus Bisnis: Cara Perhitungan Bobot, Rating dan OCAI. Jakarta: Gramedia Pustaka Utama.

Soeharjoto, Tribudhi, D. A., Hariyanti, D., \& Tajib, E. (2020). Internal and External Factor that Influence Liquidity: Case of Conventional Banks in Indonesia. International Journal of Scientific and Technology Research, 9(3), 7066-7070.

Soekapdjo, S., Tribuddhi, D. A., \& Nugroho, L. (2019). Pengaruh Fundamental Ekonomi dan Kinerja Keuangan terhadap Kredit Bermasalah Pada Bank Syariah di Indonesia. Ekonika: Jurnal ekonomi universitas kadiri, 4(2), 126-139.

https://doi.org/http://dx.doi.org/10.30737/ekon ika.v4i2.327

Taga, A., Nawawi, K., \& Kosim, A. M. (2019). Perkembangan Perbankan Syariah Sebelum dan Sesudah Spin-Off. Tafaqquh: Jurnal Hukum Ekonomi Syariah dkan Ahwal Syahsiyah, 4(1), 78-110.

Winarto, W. W. A., \& Falah, F. (2020). Analisis Sistem Pengelolaan Keuangan Produk Pembiayaan Syariah dengan Akad Murabahah. JPS (Jurnal Perbankan Syariah), 1(2), 150-161.

https://doi.org/https://doi.org/10.46367/jps.v1i 2.234

Yunus, M., Hamdani, F. F. R. S., \& Shofia, G. K. (2018). Tinjauan Fikih Muamalah terhadap Akad Jual Beli dalam Transaksi Online pada Aplikasi Go-Food. Amwaluna: Jurnal Ekonomi dan Keuangan Syariah, 2(1), 135-146. https://doi.org/https://doi.org/10.29313/amwal una.v2i1.3363 134 